\title{
Only $7 \%$ of the variation in feed efficiency in veal calves can be predicted from variation in feeding motivation, digestion, metabolism, immunology, and behavioral traits in early life
}

\author{
M. S. Gilbert, ${ }^{* 1}$ J. J. G. C. van den Borne, ${ }^{* 2}$ C. G. van Reenen, $†$ and W. J. J. Gerrits ${ }^{*}$ \\ ${ }^{*}$ Animal Nutrition Group, Wageningen University and Research, $6700 \mathrm{AH}$, Wageningen, the Netherlands \\ †Livestock Research, Wageningen University and Research, $6700 \mathrm{AH}$, Wageningen, the Netherlands
}

\begin{abstract}
High interindividual variation in growth performance is commonly observed in veal calf production and appears to depend on milk replacer (MR) composition. Our first objective was to examine whether variation in growth performance in healthy veal calves can be predicted from early life characterization of these calves. Our second objective was to determine whether these predictions differ between calves that are fed a highor low-lactose MR in later life. A total of 180 male Holstein-Friesian calves arrived at the facilities at $17 \pm$ $3.4 \mathrm{~d}$ of age, and blood samples were collected before the first feeding. Subsequently, calves were characterized in the following $9 \mathrm{wk}$ (period 1) using targeted challenges related to traits within each of 5 categories: feeding motivation, digestion, postabsorptive metabolism, behavior and stress, and immunology. In period 2 (wk 10-26), 130 calves were equally divided over 2 MR treatments: a control MR that contained lactose as the only carbohydrate source and a low-lactose MR in which $51 \%$ of the lactose was isocalorically replaced by glucose, fructose, and glycerol (2:1:2 ratio). Relations between early life characteristics and growth performance in later life were assessed in 117 clinically healthy calves. Average daily gain (ADG) in period 2 tended to be greater for control calves $(1,292 \pm 111 \mathrm{~g} / \mathrm{d})$ than for calves receiving the low-lactose MR (1,267 \pm $103 \mathrm{~g} / \mathrm{d}$ ). Observations in period 1 were clustered per category using principal component analysis, and the resulting principal components were used to predict performance in period 2 using multiple regression procedures. Variation in observations in period 1 predicted $17 \%$ of variation in ADG in period 2. However, this
\end{abstract}

Received December 2, 2016.

Accepted July 3, 2017.

${ }^{1}$ Corresponding author: myrthe.gilbert@wur.nl

${ }^{2}$ Present address: Schippers Europe B.V., Rond Deel 12, $5531 \mathrm{AH}$ Bladel, the Netherlands. was mainly related to variation in solid feed refusals. When ADG was adjusted to equal solid feed intake, only $7 \%$ of the variation in standardized ADG in period 2 , in fact reflecting feed efficiency, could be explained by early life measurements. This indicates that $>90 \%$ of the variation in feed efficiency in later life could not be explained by early life characterization of the calves. It is speculated that variation in health status explains a substantial portion of variation in feed efficiency in later life. Significant relations between fasting plasma glucose concentrations, fecal $\mathrm{pH}$, drinking speed, and plasma natural antibodies in early life (i.e., not exposed to the lactose replacer) and feed efficiency in later life depended on MR composition. These measurements are therefore potential tools for screening calves in early life on their ability to cope with MR varying in lactose content.

Key words: veal calf, feed efficiency, growth performance, lactose, glycerol

\section{INTRODUCTION}

High interindividual variation in growth performance is commonly observed in veal calf production. For instance, the coefficient of variation $(\mathbf{C V})$ in ADG in healthy calves fed equal levels of nutrient intake was $5.9 \%$ for calves aged 13 to 26 wk (Gilbert et al., 2015b), $12.3 \%$ for calves aged approximately 6.5 to $9.5 \mathrm{wk}$ (Labussière et al., 2008), and $21.3 \%$ for calves aged 3 to 6 wk (Akinyele and Harshbarger, 1983). This interindividual variation occurs in the absence of clinical disease and at similar nutrient intake and therefore results mainly from variation in feed efficiency. Variation in feed efficiency can originate from variation in many biological processes. Assessing the ability of calves to respond to specific stimuli related to biological sources of variation might explain the variation in feed efficiency. We therefore designed targeted measurements related to feeding motivation, digestion, postabsorptive metabolism, behavior and stress, and immunology to characterize calves in early life kept under equal feeding 
and husbandry conditions. If these early life measures show genetic variation and thus consistency over time and are related to feed efficiency, such an early life characterization could be predictive of later life feed efficiency in healthy calves. Indeed, in beef cattle divergently selected for residual feed intake (a measure for feed efficiency), variation in feeding patterns, feed digestion, protein turnover, tissue metabolism, heat production, activity, and stress contributed to variation in feed efficiency (Herd et al., 2004; Richardson and Herd, 2004; Herd and Arthur, 2009). These phenotypic measures explained most of the genetic variation in residual feed intake. Such relations between animal characteristics and feed efficiency suggest that these characteristics could be used as early life measures to predict later life feed efficiency in veal calves.

Veal calves are fed milk replacers (MR), which commonly contain 40 to $50 \%$ lactose. High and fluctuating dairy prices are a major economic incentive to replace lactose from MR with alternative energy sources. However, differences in growth rates between individual calves increased further when lactose was replaced from the MR. For instance, the CV in ADG increased from 5.9 to $8.4 \%$ when lactose was partially replaced with maltose, although ADG decreased (Gilbert et al., 2015b). This illustrates that variation in growth performance depends on MR composition and that not all calves are equally able to cope with lactose replacers (i.e., lowlactose MR). Digestive and metabolic processes may contribute to this increase in interindividual variation in growth performance when feeding low-lactose MR. For example, the CV in apparent ileal disappearance of DM increased from 5.0 to $6.9 \%$ when partly replacing lactose with maltose (Gilbert et al., 2015a), and the CV in urinary glucose excretion increased from 42 to $82 \%$ when partly replacing lactose with glucose, fructose, or glycerol (Gilbert et al., 2016). Predictions of feed efficiency of calves from traits measured in early life might therefore differ between calves fed a high- or low-lactose MR. Our objectives were (1) to examine whether variation in growth performance of healthy veal calves can be predicted from early life characterization of these calves and (2) to determine whether these predictions differ between calves that are fed a high- or low-lactose MR in later life.

\section{MATERIALS AND METHODS}

This experiment was conducted at the research facilities of the VanDrie Group (Scherpenzeel, the Netherlands) and was submitted to and approved by the Animal Care and Use Committee of Wageningen University (Wageningen, the Netherlands).

\section{Experimental Design}

The experiment consisted of 2 periods. Period 1 started when calves arrived at the experimental facilities, and measurements were performed from experimental wk 1 to 9 on individual calves to characterize each calf. In period 2 , the feeding trial was conducted in which a control, lactose-based MR was compared with an MR in which $51 \%$ of the lactose was replaced with glucose, fructose, and glycerol. Period 2 lasted from experimental wk 10 to 28, and general performance was recorded.

\section{Animals, Housing, and Feeding}

Calves were housed on wooden slatted floors throughout the experiment. Light was provided by daylight, and artificial lights were on from 0600 to $1800 \mathrm{~h}$. The stable was mechanically ventilated. The temperature and humidity averaged $19 \pm 3.9^{\circ} \mathrm{C}$ and $77 \pm 9.3 \%$ (mean $\pm \mathrm{SD}$ ), respectively.

Period 1. A total of 180 male Holstein-Friesian calves of Dutch origin arrived at the experimental facilities at $17 \pm 3.4 \mathrm{~d}$ of age and $44 \pm 2.6 \mathrm{~kg}$ of BW (mean $\pm \mathrm{SD}$ ). Calves were housed individually in a $1.2-\mathrm{m}^{2}$ pen so that all measurements could be performed individually.

The ingredient and nutrient composition of the experimental MR are shown in Table 1. Calves received MR with lactose as the only carbohydrate source. Solid feed comprised concentrates, rapeseed straw, and alfalfa and was supplied at a ratio of 70:15:15 on an estimated DM basis. Concentrates comprised oats, $250 \mathrm{~g} / \mathrm{kg}$; barley, $238 \mathrm{~g} / \mathrm{kg}$; corn, $201 \mathrm{~g} / \mathrm{kg}$; lupines, $155 \mathrm{~g} / \mathrm{kg}$; corn gluten meal, $111 \mathrm{~g} / \mathrm{kg}$; vitamin-mineral mix, $24 \mathrm{~g} / \mathrm{kg}$; and molasses, $20 \mathrm{~g} / \mathrm{kg}$. Analyzed CP content was $183 \mathrm{~g} /$ $\mathrm{kg}$. The feeding levels for MR and solid feed were based on a practical feeding scheme and were equal between calves. Milk replacer allowance increased progressively from 400 to $1,200 \mathrm{~g} / \mathrm{d}$, and solid feed increased from 85 to $360 \mathrm{~g} / \mathrm{d}$. Solid feed was provided from 1 wk after arrival onward. The MR was mixed with warm water $\left(66^{\circ} \mathrm{C}\right)$, and the concentration of reconstituted $\mathrm{MR}$ was $125 \mathrm{~g} / \mathrm{kg}$. Reconstituted MR was supplied at a temperature of approximately $42^{\circ} \mathrm{C}$ in 2 equal meals, at 0600 and $1600 \mathrm{~h}$, and calves were allowed access for 15 min, after which refusals were quantified. Solid feed was provided to each calf individually directly after the morning MR meal. Solid feed refusals were removed and quantified before the morning meal. Water was available through water nipples continuously except for $2 \mathrm{~h}$ around MR feeding.

Period 2. Age and BW at the start of period 2 were $82 \pm 3.5 \mathrm{~d}$ and $87 \pm 4.1 \mathrm{~kg}$ (mean $\pm \mathrm{SD}$ ), respectively. Calves were housed in groups of 5 in a pen of $9 \mathrm{~m}^{2}$. Each calf was assigned to 1 of $2 \mathrm{MR}$ treatments: a con- 
trol MR with lactose as the only carbohydrate source or an MR in which $51 \%$ of the lactose was replaced with a mixture of glucose, fructose, and glycerol in a 2:1:2 ratio on a gross energy basis (GFG; Table 1). Solid feed comprised concentrates and rapeseed straw and was supplied at a ratio of 80:20 on an estimated DM basis. Milk replacer allowance increased progressively from 1,250 to $3,000 \mathrm{~g} / \mathrm{d}$, and solid feed supply increased from 630 to $1,170 \mathrm{~g} / \mathrm{d}$. Reconstituted MR concentration increased from 125 to a maximum of 200 $\mathrm{g} / \mathrm{kg}$. Solid feed was provided to each calf individually directly after the MR meal at 0600 and $1600 \mathrm{~h}$. The calves were allowed to consume their solid feed portion for $60 \mathrm{~min}$, after which solid feed refusals were removed and quantified. During feeding of MR and solid feed, calves were fixed in the headlock of the fence to enable individual feeding. Water was available ad libitum through water nipples.

Table 1. Ingredient and nutrient composition of the experimental milk replacers

\begin{tabular}{|c|c|c|c|}
\hline Item & Period 1 & \multicolumn{2}{|c|}{ Period 2} \\
\hline \multicolumn{4}{|l|}{ Ingredient, $\mathrm{g} / \mathrm{kg}$} \\
\hline Lactose or lactose replacement ${ }^{1}$ & & \multicolumn{2}{|c|}{$250.0^{1}$} \\
\hline Whey & 466.1 & \multicolumn{2}{|c|}{201.9} \\
\hline Delactosed whey & 149.7 & \multicolumn{2}{|c|}{150.0} \\
\hline Whey protein concentrate & 111.3 & \multicolumn{2}{|c|}{85.2} \\
\hline Soy protein concentrate & 10.0 & \multicolumn{2}{|c|}{62.5} \\
\hline Soluble wheat protein & 64.1 & \multicolumn{2}{|c|}{38.6} \\
\hline \multicolumn{4}{|l|}{ Fat } \\
\hline Lard & 52.5 & \multicolumn{2}{|c|}{64.6} \\
\hline Tallow & 52.5 & \multicolumn{2}{|c|}{64.6} \\
\hline Coconut oil & 49.2 & \multicolumn{2}{|c|}{34.9} \\
\hline Lecithin & 5.0 & \multicolumn{2}{|c|}{5.2} \\
\hline Emulsifier & 5.0 & \multicolumn{2}{|c|}{5.2} \\
\hline Premix & $10.0^{2}$ & \multicolumn{2}{|c|}{$10.0^{3}$} \\
\hline Calcium formate & 8.4 & \multicolumn{2}{|c|}{7.5} \\
\hline Mono ammonium phosphate & & \multicolumn{2}{|c|}{5.7} \\
\hline Lysine & 10.0 & \multicolumn{2}{|c|}{6.7} \\
\hline Methionine & 2.1 & \multicolumn{2}{|c|}{3.1} \\
\hline Threonine & 2.0 & \multicolumn{2}{|c|}{1.6} \\
\hline $\mathrm{CaCO}_{3}$ & 2.5 & \multicolumn{2}{|c|}{2.5} \\
\hline Nutrient, $\mathrm{g} / \mathrm{kg}$ of DM unless noted & & Control & $\mathrm{GFG}^{4}$ \\
\hline $\mathrm{DM}, \mathrm{g} / \mathrm{kg}$ & 978 & 980 & 973 \\
\hline Crude ash & 86 & 63 & 63 \\
\hline $\mathrm{CP}, \mathrm{N} \times 6.25$ & 207 & 180 & 181 \\
\hline Crude fat & 193 & 205 & 187 \\
\hline Lactose $^{1,5}$ & 473 & 504 & 266 \\
\hline $\mathrm{Fe}, \mathrm{mg} / \mathrm{kg}$ of $\mathrm{DM}$ & 45.9 & 12.2 & 12.9 \\
\hline
\end{tabular}

${ }^{1}$ In period 2, 2 milk replacers were used. In the GFG milk replacer, lactose was replaced by $100 \mathrm{~g} / \mathrm{kg}$ of glucose, $50 \mathrm{~g} / \mathrm{kg}$ of fructose, and $97.8 \mathrm{~g} / \mathrm{kg}$ of glycerol. The amount of glycerol was slightly adjusted to match the gross energy content of the combination of glucose, fructose, and glycerol with that of the replaced lactose. Gross energy content was $15.6 \mathrm{~kJ} / \mathrm{g}$ for lactose, $14.0 \mathrm{~kJ} / \mathrm{g}$ for glucose, $15.4 \mathrm{~kJ} / \mathrm{g}$ for fructose, and $17.6 \mathrm{~kJ} / \mathrm{g}$ for glycerol.

${ }^{2}$ The starter premix provided (per $\mathrm{kg}$ of experimental diet) $\mathrm{CP}, 0.7 \mathrm{~g}$; starch, $5.0 \mathrm{~g}$; crude ash, $1.5 \mathrm{~g}$; calcium, $16.6 \mathrm{mg}$; phosphorus, $7.5 \mathrm{mg}$; sodium, $0.7 \mathrm{mg}$; potassium, $7.3 \mathrm{mg}$; chloride, $13.1 \mathrm{mg}$; magnesium, $0.5 \mathrm{~g}$; iron, 44 mg; copper, $8.0 \mathrm{mg}$; zinc, $110 \mathrm{mg}$; manganese, $43 \mathrm{mg}$; selenium, $0.3 \mathrm{mg}$; iodide, $1.0 \mathrm{mg}$; vitamin A, 25,013 IU; vitamin $\mathrm{D}_{3}$, 4,002 IU; vitamin $\mathrm{E}, 135 \mathrm{mg}$; vitamin $\mathrm{C}$, $0.3 \mathrm{~g}$; vitamin $\mathrm{K}_{3}, 2.1 \mathrm{mg}$; vitamin $\mathrm{B}_{1}, 8.2 \mathrm{mg}$; vitamin $\mathrm{B}_{2}, 10.2 \mathrm{mg}$; vitamin $\mathrm{B}_{3}, 34.9 \mathrm{mg}$; vitamin $\mathrm{B}_{5}, 18.0 \mathrm{mg}$; vitamin $\mathrm{B}_{6}, 10.0 \mathrm{mg}$; vitamin $\mathrm{B}_{12}, 0.1 \mathrm{mg}$; biotin, 0.2 $\mathrm{mg}$; choline, $0.4 \mathrm{~g}$; and folic acid, $0.7 \mathrm{mg}$.

${ }^{3}$ The finisher premix provided (per kg of experimental diet) CP, $0.8 \mathrm{~g}$; starch, $5.4 \mathrm{~g}$; crude ash, $1.3 \mathrm{~g}$; calcium, $17.0 \mathrm{mg}$; phosphorus, $8.1 \mathrm{mg}$; sodium, $0.8 \mathrm{mg}$; potassium, $7.8 \mathrm{mg}$; chloride, $13.2 \mathrm{mg}$; magnesium, $0.5 \mathrm{~g}$; iron, $0.3 \mathrm{mg}$; copper, $4.0 \mathrm{mg}$; zinc, $100 \mathrm{mg}$; manganese, $43 \mathrm{mg}$; selenium, $0.3 \mathrm{mg}$; iodide, $1.0 \mathrm{mg}$; vitamin A, 25,000 IU; vitamin $\mathrm{D}_{3}, 4,000 \mathrm{IU}$; vitamin $\mathrm{E}, 90 \mathrm{mg}$; vitamin $\mathrm{C}, 0.1 \mathrm{~g}$; vitamin $\mathrm{K}_{3}, 2.1 \mathrm{mg}$; vitamin $\mathrm{B}_{1}, 8.2 \mathrm{mg}$; vitamin $\mathrm{B}_{2}, 10.2 \mathrm{mg}$; vitamin $\mathrm{B}_{3}, 34.8 \mathrm{mg}$; vitamin $\mathrm{B}_{5}, 18.0 \mathrm{mg}$; vitamin $\mathrm{B}_{6}, 6.2 \mathrm{mg}$; vitamin $\mathrm{B}_{12}, 0.1 \mathrm{mg}$; biotin, 0.2 $\mathrm{mg}$; choline, $0.4 \mathrm{~g}$; and folic acid, $0.7 \mathrm{mg}$.

${ }^{4}$ In the GFG milk replacer, glycerol was liquid and added separately when milk was prepared. The milk replacer powder without glycerol was analyzed on nutrient content. Glycerol was assumed to contain $995 \mathrm{~g} / \mathrm{kg}$ of glycerol and $5 \mathrm{~g} / \mathrm{kg}$ of moisture based on product specifications.

${ }^{5}$ Calculated content 


\section{Measurements}

Health and performance of the calves were regularly monitored. Calves were weighed once every 4 wk. Hemoglobin $(\mathbf{H b})$ concentration in jugular blood was determined in 4-wk intervals. A minimum $\mathrm{Hb}$ concentration of $5.5 \mathrm{mmol} / \mathrm{L}$ was targeted, and iron was injected intramuscularly when necessary. Rectal temperature was taken at 2 -wk intervals to help identify clinically ill calves. Medical treatment was applied when required based on clinical signs of illness, and all treatments were recorded. These regular measures (rectal temperature and $\mathrm{Hb}$ ) were not used as early life measurements in the statistical analyses except for the $\mathrm{Hb}$ measurement upon arrival of the calves.

Period 1 Measurements. The IgG concentration in plasma of neonatal calves is related to the quantity and quality of colostrum intake (Morin et al., 1997; Hammon and Blum, 1998). Blood samples were therefore collected at arrival before the first feeding as an indicator of the individual conditions upon arrival. A jugular blood sample was collected by venipuncture in lithium heparin tubes to determine hematocrit and the titers of natural antibodies (IgG and IgM). Blood was transferred to nonheparinized capillaries and centrifuged at $9,600 \times g$ for 4 min using a microcentrifuge (Heraeus Pico 17; Thermo Scientific, Waltham, MA), and the percentage of red blood cells was calculated. Plasma was harvested from the remaining blood after centrifugation and stored at $-20^{\circ} \mathrm{C}$ pending $\operatorname{IgG}$ and IgM titer analyses. In addition, a second blood sample was taken and analyzed for $\mathrm{Hb}$ concentration. No iron was administered following this first $\mathrm{Hb}$ check. In wk 5 , 1 fecal sample was taken directly from the rectum and analyzed for the presence of pathogens (rotavirus, coronavirus, Escherichia coli K99, and Cryptosporidium) using an immunoassay (BIO K 288; Bio-X Diagnostics, Rochefort, Belgium). In wk 2 and 6 , calf shape was measured. Heart girth and body length were measured to calculate the surface area of the body, assuming a cylinder and calculating surface area as $\left(2 \pi \times r^{2}\right)+(\pi$ $\times d \times h)$, where $r=$ heart girth $/ 2 \pi, d=2 \times r$, and $h=$ body length. Surface area was divided by BW to assess calf shape $\left(\mathrm{cm}^{2} / \mathrm{kg}\right.$ of $\left.\mathrm{BW}\right)$. In addition, measurements were performed to characterize the calves. Most of these measurements were designed as challenges because these will likely cause more variation between animals, especially for metabolic measures under strong homeostatic control (Blair et al., 1990). Targeted challenges were performed related to the following categories: feeding motivation, digestion, postabsorptive metabolism, behavior and stress, and immunology.

Feeding Motivation. Feeding motivation for MR and concentrates was tested in wk 8 and 9, respectively, during a single ad libitum intake test, replacing the normal feeding that was $4.6 \mathrm{~kg}$ of reconstituted MR and $330 \mathrm{~g}$ of solid feed. For the test with MR, $14 \mathrm{~kg}$ of reconstituted MR was provided, and unrestricted access was allowed for $10 \mathrm{~min}$. For the test with concentrates, 500-g portions were provided hourly for $3 \mathrm{~h}$ after the normal MR meal, which was $4.8 \mathrm{~kg}$ of reconstituted MR, and calves were stimulated to stand up at each portion of concentrates provided. In addition, the drinking speed of $4.6 \mathrm{~kg}$ of reconstituted MR was measured in wk 8 during a morning and afternoon MR meal and expressed in kilograms of reconstituted MR per minute.

Digestion. In beef cattle, total-tract DM digestibility contributed $10 \%$ to the variation in residual feed intake (Richardson and Herd, 2004). Dry matter content of the feces is associated with apparent total-tract DM digestibility in pigs (Elbers et al., 1989) and milk-fed calves (Gilbert et al., 2015a) and therefore could be used as an indicator to explain variation in feed efficiency. Therefore, 1 fecal sample was taken directly from the rectum in wk 5, and fecal $\mathrm{pH}$ (Hanna Instruments, type HI 9024; Woonsocket, RI) and DM content were measured. Feces were scored on consistency (1-5: thin, normal/thin, normal, firm/normal, and firm) and color (1-7: white, yellow, light brown, brown, dark brown, gray, and black) 9 times during period 1 (once or twice per week in wk 1-6 and once in wk 10). Mean fecal consistency and color score were calculated. In wk 6 , retention time of $4.2 \mathrm{~kg}$ of reconstituted MR was determined by adding $53 \mathrm{mg}$ of $\mathrm{CrCl}_{3}$ hexahydrate/g of $\mathrm{MR}$ as an indigestible colored marker (Benvenutti et al., 2014) to the MR meal and scoring the first appearance of the green color in the feces by hourly scan sampling for $28 \mathrm{~h}$.

Postabsorptive Metabolism. In beef cattle, residual feed intake and plasma insulin concentration tended to be genetically related (Richardson et al., 2004). In addition, protein turnover was identified to contribute to variation in feed efficiency in beef cattle (Richardson and Herd, 2004). Indicators of protein catabolism, such as urea production, could therefore be used to explain variation in feed efficiency. In wk 7 , after overnight fasting, postabsorptive metabolism was assessed during an MR meal challenge followed by a fasting challenge. Milk replacer was provided with a movable MR mixer and dispenser. Milk replacer supply was calculated as the difference between the weighed amount of MR before feeding and the remaining $\mathrm{MR}$ in the dispenser after feeding divided by the number of calves fed per feeding round (20 calves/feeding round), and MR supply was $506 \pm 13 \mathrm{~g}$ (mean $\pm \mathrm{SD})$. Each individual MR meal was supplemented with $41 \mathrm{mg}$ of ${ }^{13} \mathrm{C}$ urea (99 atom\%; Sigma-Aldrich, St. Louis, MO). Jugular blood samples 
were collected by venipuncture at -1.6 (basal), 1, 2, 6 , 15, and $24 \mathrm{~h}$ after MR feeding in lithium heparin tubes for insulin, ${ }^{13} \mathrm{C}$ urea, and IGF-1 analysis and in sodium fluoride tubes for glucose, L-lactate, and nonesterified fatty acid (NEFA) analysis. Plasma was harvested after centrifugation and stored at $-20^{\circ} \mathrm{C}$ pending analysis for glucose (all samples), insulin (-1.6, 1, 2, 6, and 15 h), L-lactate (all samples), NEFA (all samples), and ${ }^{13} \mathrm{C}$ urea enrichment (all postprandial time points for 10 randomly selected calves and for other calves at 1, 6, and $15 \mathrm{~h}$ after feeding). It can be expected that dilution of plasma ${ }^{13} \mathrm{C}$ urea is caused by endogenous urea production by the calf after ${ }^{13} \mathrm{C}$ urea absorption; therefore, the rate of ${ }^{13} \mathrm{C}$ urea dilution can be used as an indicator for urea production, as shown in pigs by Oosterveld et al. (2005). Moore et al. (2005) found a strong genetic correlation between plasma IGF-1 concentration measured before and after weaning in Angus cattle, and plasma IGF-1 was genetically correlated with residual feed intake. Therefore, IGF-1 was analyzed in the -1.6 $\mathrm{h}$ plasma samples. For the meal challenge, calculated variables included the increase in plasma glucose, Llactate, and insulin from basal to peak, which was 1 or $2 \mathrm{~h}$ postprandial, and the decrease in plasma NEFA from basal to $1 \mathrm{~h}$ postprandial. For the fasting challenge, variables included the decrease in plasma glucose and the increase in plasma NEFA concentration from 15 to $24 \mathrm{~h}$ after feeding and the decrease in ${ }^{13} \mathrm{C}$ urea enrichment from 6 to $15 \mathrm{~h}$ after feeding.

Behavior and Stress. Acceptance of Angus calves to being restrained (Kilgour et al., 2006), reactivity to novelty of Holstein-Friesian heifers (van Reenen et al., 2005), and flight speed from a weighing crate in steers (Petherick et al., 2002) appear consistent over time, and such behavioral traits of cattle can be associated with performance (Petherick et al., 2002; Cafe et al., 2011). In pigs divergently selected for residual feed intake for 6 generations, less efficient pigs had a higher fasting- and activity-related heat production (Barea et al., 2010), of which the latter was partially related to differences in feeding behavior (Gilbert et al., 2009). Behavioral measurements were therefore also performed. In wk 7, a human approach test was performed during the morning and afternoon feedings as described by Lensink et al. (2003). In short, in phase 1 (i.e., approach phase), 1 person approached a drinking calf and noted whether the calf stopped drinking. In phase 2 (i.e., touch phase), the withdrawal reaction of the calf to the outstretching arm of the approaching person was scored from 1 (no withdrawal) to 4 (strong withdrawal reaction) $10 \mathrm{~min}$ after phase 1. For both phases, the mean score of each calf was calculated.
In wk 7 , physical activity of calves was measured using scan sampling. During $3 \mathrm{~d}$, the posture (standing or lying) of the calf was scored $2.5 \mathrm{~h}$ after the morning feeding and $2.5 \mathrm{~h}$ before the afternoon feeding, resulting in 48 scans per calf. Activity was expressed as the percentage of the scans in which the calf was standing.

In wk 8, a restraint test was performed for each calf. After taking a basal blood sample, calves were restrained with a halter, which they had not been in contact with before, and the halter was connected to the feeding fence. After $12 \mathrm{~min}$, a second blood sample was taken and the halter was removed. Blood samples were collected by venipuncture in lithium heparin tubes, and plasma was harvested after centrifugation and stored at $-20^{\circ} \mathrm{C}$ pending cortisol analysis. The increase in cortisol concentration in reaction to restraining was calculated as a proxy for acute stress.

In wk 10, the calf's behavior during routine weighing was recorded during 2 phases. First, the animal caretaker opened the individual pen and the movement behavior of the calf toward the weighing scale was qualitatively assessed using a 5-point score from 1 (calf is resistant and does not move; the animal caretaker has to push the calf toward the weighing scale) to 5 (the calf runs toward the weighing scale). Second, the behavior of the calf during fixation on the weighing scale was scored from 1 (calf does not move) to 4 (calf is very restless and moves continuously).

Immunology. In wk 9, a LPS challenge was performed. The LPS from Escherichia coli 055:B5 (L6529, Sigma-Aldrich) was dissolved in saline solution at a concentration of $1 \mu \mathrm{g} / \mathrm{mL}$ and injected in the jugular vein at $0.05 \mu \mathrm{g} / \mathrm{kg}$ of BW (Borderas et al., 2008). Rectal temperature and respiratory frequency were recorded before injection and every hour after injection up to $8 \mathrm{~h}$.

Period 2 Measurements. Measurements related to performance and health were performed as described above. In addition, one measurement as part of the characterization of the calves from the category immunology was included because this measurement could not be performed earlier for logistic reasons. Calves were subjected to a human serum albumin (HuSa) challenge in wk 11. Calves with a rectal temperature $>40^{\circ} \mathrm{C}$ were excluded. The HuSa (A8763; Sigma-Aldrich) was dissolved in saline solution at a concentration of $1 \mathrm{mg} / \mathrm{mL}$ and was injected intramuscularly at $50 \mu \mathrm{g} / \mathrm{kg}$ of BW. Blood samples were collected in lithium heparin tubes by venipuncture before HuSa injection and at 3, 7, 14, and $28 \mathrm{~d}$ after $\mathrm{HuSa}$ injection. Plasma was harvested after centrifugation and stored at $-20^{\circ} \mathrm{C}$ pending specific IgG and IgM titer analyses. 


\section{Analytical Procedures}

Milk replacers were sampled and analyzed for DM (ISO, 1999b), nitrogen (NEN, 1984), crude fat (ISO, 1999a), and crude ash (ISO, 2002). Fecal samples were thawed, homogenized, and analyzed for DM according to ISO (1999b) standard number 6496. Concentrates were analyzed for nitrogen (ISO, 2005).

Plasma samples from the meal and fasting challenges were analyzed for glucose and L-lactate enzymatically using the Roche/Hitachi Modular P800 automatic analyzer (Roche Diagnostics, Mannheim, Germany), and the between- and within-run CV were $\leq 2 \%$. The concentration of NEFA was analyzed enzymatically using a kit (NEFA FS kit, DiaSys, Holzheim, Germany), and absorbance was measured with a spectrophotometer (Selectra ProM, EliTech Clinical Systems, Logan, UT). The between- and within-run CV were $\leq 2 \%$. Insulin concentration was analyzed with ELISA (Bovine Insulin ELISA kit; Mercodia, Uppsala, Sweden) with a between-run $\mathrm{CV}$ of $\leq 5.6 \%$ and a within-run $\mathrm{CV}$ of $8.2 \%$. For the determination of ${ }^{13} \mathrm{C}$ enrichment in urea, plasma samples were derivatized and analyzed using combustion isotope ratio mass spectrometry (Finnigan Delta V advantage; Finnigan MAT, Bremen, Germany) as described by Dai et al. (2010), with a between-run CV of $10.6 \%$ and a within-run CV of $3.5 \%$. Cortisol and IGF-1 were analyzed by immunoassay using an Immulite 2000 analyzer (Siemens, Munich, Germany) with a between-run CV of 11.3 and $5.4 \%$, respectively.

Plasma samples collected when calves arrived at the experimental facilities were analyzed for natural antibody titers $[\operatorname{IgG}$ and IgM, binding keyhole limpet hemocyanin $(\mathbf{K L H})$ ], and plasma samples from the $\mathrm{HuSa}$ challenge were analyzed for specific antibody titers (IgG and IgM binding HuSa) by ELISA. In short, 96well plates were coated with $100 \mu \mathrm{L} /$ well of $4 \mu \mathrm{g} / \mathrm{mL}$ of KLH (H8283; Sigma-Aldrich) or HuSa (A8763; SigmaAldrich), incubated overnight at $4^{\circ} \mathrm{C}$, and washed with tap water containing $0.05 \%$ Tween20. Plasma samples were added to the plates in a 4-step serial dilution starting with dilution 1:40, and plates were incubated for $1.5 \mathrm{~h}$ at room temperature with 1:20,000 diluted sheep antibovine $\operatorname{IgG}$ heavy chain $[\mathrm{Sh} \alpha \mathrm{BoIgG}(\mathrm{Fc}) /$ PO, A10-118P; Bethyl, Montgomery, TX] and rabbit anti-bovine $\operatorname{IgM}[\mathrm{R} \alpha \mathrm{BoIgM}(\mathrm{Fc}) / \mathrm{PO}, \mathrm{A} 10-100 \mathrm{P}$; Bethyl] for IgG and IgM, respectively. After washing, tetramethylbenzidine and $0.05 \% \mathrm{H}_{2} \mathrm{O}_{2}$ were added and the plates were incubated for $10 \mathrm{~min}$ at room temperature. Reactions were stopped with $1.25 \mathrm{M} \mathrm{H}_{2} \mathrm{SO}_{4}$, and extinctions were measured with a multiscan instrument (Labsystems, Helsinki, Finland) at a wavelength of 450 $\mathrm{nm}$. The highest mean extinction of a standard positive pooled plasma sample $\left(\mathbf{E}_{\max }\right)$, which was added to each microtiter plate, was calculated. Values of the dilutions that gave an extinction closest to $50 \%$ of $\mathrm{E}_{\max }$ were used and titers were expressed as $\log _{2}$ values. The between-plate and within-plate CV were 9.3 and $2.8 \%$ for IgG binding $\mathrm{KLH}, 4.1$ and $3.5 \%$ for IgM binding $\mathrm{KLH}, 10.6$ and $1.2 \%$ for IgG binding HuSa, and 6.7 and $2.7 \%$ for IgM binding HuSa, respectively.

\section{Statistical Analyses}

The objective was to relate the calves' capacity to cope with physiological and behavioral challenges in early life to growth performance in later life. In our statistical approach, we first subjected the measured parameters (see the Measurements section) in early life to a principal component analysis (PCA) for each category (i.e., arrival, feeding motivation, digestion, postabsorptive metabolism, and behavior and stress) to reduce and scale the data. Thereafter, factor scores were extracted for all calves for all principal components (PC) retained in the PCA of each category. Finally, the relation between these $\mathrm{PC}$, their interaction with MR treatment in period 2, and growth performance in period 2 was determined with multiple regression analysis.

In this experiment, we anticipated including at least 120 clinically healthy calves in which the measurements were performed successfully. Therefore, we initially included 180 calves in period 1 . The LPS challenge was performed in 32 calves, but because of the unexpected shock resulting in the death of 4 calves, this challenge was not performed for the other calves, and the 28 calves remaining after the LPS challenge were removed from the experiment. In addition, calves with extensive individual medical treatments in period 1 were excluded. Consequently, 130 calves were included in period 2. The category immunology included only the HuSa challenge (i.e., specific IgG and IgM response) and was therefore not subjected to PCA.

All statistical procedures were performed with SAS 9.3 (SAS Institute Inc., Cary, NC). The PCA was performed with the principal axis method of the FACTOR procedure, and prior communality estimates were set at 1 . Extracted PC were subjected to varimax rotation, and $\mathrm{PC}$ with an eigenvalue $>1$ were retained for further analysis. In the rotated factor pattern, variables with a loading $\geq 0.40$ or $\leq-0.40$ were considered to load on that PC. To evaluate whether the categories in period 1 had common underlying mechanisms, a secondary PCA was performed on all the retained PC per category, plasma IGF-1 concentration, and calf shape. Pearson correlation coefficients were estimated using the CORR procedure. Results are expressed as mean \pm standard deviation. 
Treatment of the Raw Data Before PCA Dealing with Missing Observations. To successfully perform PCA on the measurements per category, missing values of individual calves were replaced by the mean or median of the other calves. Two calves were considered to be missing values for the urea production data because ${ }^{13} \mathrm{C}$ enrichment in plasma urea was too low at $6 \mathrm{~h}$ after feeding (i.e., below the mean ${ }^{13} \mathrm{C}$ enrichment in plasma urea of 10 randomly selected calves at $24 \mathrm{~h}$ postprandial; 1.071 atom\%) to estimate a slope for ${ }^{13} \mathrm{C}$ urea dilution. Two calves were considered to be missing values for all variables related to the meal and fasting challenges because these calves appeared to have drunk their MR in the rumen. This appeared from the low increase in ${ }^{13} \mathrm{C}$ enrichment in plasma urea $(<0.005$ atom\%) from 1 to $6 \mathrm{~h}$ postprandial, a postprandial increase in plasma glucose $<1 \mathrm{mmol} / \mathrm{L}$, and the absence of a postprandial decrease in plasma NEFA concentration. For fecal DM and pH, 16 calves were considered missing values as they tested positive on fecal pathogens. Additional analyses revealed that fecal pathogens were related to fecal DM $(P=0.021)$ and $\mathrm{pH}(P=0.023)$. For the feeding motivation test with MR and for drinking speed of MR, 11 calves were considered missing values because they used a floating drinking teat. A drinking teat was used when calves showed difficulties with drinking MR directly from the bucket at arrival at the facilities. The mode of feeding MR affected intake during the feeding motivation test $(P=0.011)$ as well as drinking speed $(P<0.001)$. Furthermore, measurements performed within $3 \mathrm{~d}$ after individual medical treatment were considered as missing values (4 calves). Measurements of retention time of MR were not included in the statistical analyses due to a combination of factors. In 14 calves, the green color was not observed in the feces. In 20 calves, more than $20 \%$ of the MR was refused. Also, the presence of fecal pathogens tended to affect retention time $(P=0.09)$, which ultimately resulted in missing values for $35 \%$ of the calves.

Computing ADG, Adjusted for Differences in Solid Feed Intake in Period 2. Despite restricted feeding, not all calves consumed their solid feed allowance, which resulted in variation in solid feed intake. Solid feed intake $(P<0.001)$ affected ADG in period 2 (GLM procedure). Therefore, ADG in period 2 was adjusted for solid feed intake in period 2 by adding the residuals (from the model: $\mathrm{ADG}$ in period $2=$ solid feed intake in period 2), to the mean ADG in period 2. This adjusted ADG is the ADG at equal solid feed intake and therefore represents feed efficiency.

Building a Model to Predict ADG in Period 2 from Traits Measured in Period 1. The effects of retained PC, MR treatment, and the interaction between retained $\mathrm{PC}$ and $\mathrm{MR}$ treatment on adjusted ADG in period 2 were analyzed. Variables not included in the PCA (i.e., the specific IgG and IgM response to HuSa injection, IGF-1 concentration, and calf shape) were also included in the models. First, the PC and abovementioned variables and the interaction with MR treatment were used in a univariate model. Principal components or interactions with the MR treatment with $P<0.2$ were selected. Second, these selected PC and interactions were included in a multivariate model. Principal components or interactions with $P>0.1$ were removed from the selection. Finally, the multivariate model with the greatest adjusted coefficient of determination and with all variables or interactions with $P$ $<0.1$ was selected. The same procedure as described above was used for selecting the model that explains most of the variation in unadjusted ADG in period 2. These models were performed with the MIXED procedure, including a random effect of pen. When an interaction effect was significant, the estimate statement was used to estimate the regression coefficient $\beta$ and the significance of $\beta$. Model residuals were checked visually on homogeneity of variance.

\section{RESULTS}

\section{General}

During the last 2 wk of period 2, an outbreak of severe diarrhea occurred. These last 2 wk were therefore not taken into account, and period 2 lasted $16 \mathrm{wk}$ instead of 18 wk. One calf was euthanized at the start of period 2 due to severe BW loss and poor condition. Three calves died in period 2 ( 2 after bloating and 1 after severe diarrhea). Calves with MR refusals $>5 \%$ in period $2(\mathrm{n}=9)$ were excluded from analyses because these calves were assumed to refuse their MR due to health problems. Therefore, 117 calves were included in statistical analyses. Milk replacer intake, solid feed intake, and ADG in period 1 averaged $53.6 \pm 0.26 \mathrm{~kg}$, $11.3 \pm 1.66 \mathrm{~kg}$, and $701 \pm 60 \mathrm{~g}$, respectively.

\section{PCA per Category of Early Life Measurements}

Descriptive data of the measurements performed in period 1 are presented in Table 2. Loadings of all variables for each PC per category are presented in Table 3. Within each category, an attempt was made to interpret loading patterns of included variables on each $\mathrm{PC}$, as described in the headings of Table 3. For the category arrival, $2 \mathrm{PC}$ (Hb and hematocrit, and natural antibodies) were retained, accounting for $90 \%$ of the total variance. For the category feeding motivation, $2 \mathrm{PC}$ (feeding motivation and drinking speed) were retained, 
accounting for $76 \%$ of the total variance. For the category digestion, $2 \mathrm{PC}$ (fecal $\mathrm{pH}$ and fecal $\mathrm{DM}$ ) were retained, accounting for $65 \%$ of the total variance. For the category postabsorptive metabolism, 5 PC (postprandial response, fasting glucose and NEFA, fasting glucose, lactate and basal insulin, and urea production)

Table 2. Descriptive data of measurements performed in early life of calves $(\mathrm{n}=117)$

\begin{tabular}{|c|c|c|c|}
\hline Item $^{1}$ & Mean & $\mathrm{SD}$ & $\mathrm{CV}$ \\
\hline \multicolumn{4}{|l|}{ Arrival } \\
\hline Hematocrit, \% & 33.5 & 5.80 & 17.3 \\
\hline Hemoglobin, mmol/L & 6.2 & 1.09 & 17.6 \\
\hline IgG titer & 3.2 & 1.38 & 42.7 \\
\hline IgM titer & 4.3 & 1.53 & 35.1 \\
\hline \multicolumn{4}{|l|}{ Feeding motivation } \\
\hline Milk replacer, kg & 10.4 & 1.16 & 11.2 \\
\hline Concentrates, kg & 0.32 & 0.24 & 74.0 \\
\hline Drinking speed, $\mathrm{kg}$ of milk replacer/min & 4.4 & 1.74 & 39.2 \\
\hline \multicolumn{4}{|l|}{ Digestion } \\
\hline Fecal DM content, $\mathrm{g} / \mathrm{kg}$ & 179 & 26.8 & 15.0 \\
\hline Fecal pH & 7.3 & 0.32 & 4.3 \\
\hline Fecal consistency score & 3.1 & 0.36 & 11.5 \\
\hline Fecal color score & 3.8 & 0.30 & 7.9 \\
\hline Total-tract retention time, $\mathrm{h}$ & 12.2 & 1.77 & 14.4 \\
\hline \multicolumn{4}{|l|}{ Postabsorptive metabolism } \\
\hline \multicolumn{4}{|l|}{ Meal challenge } \\
\hline Basal glucose, mmol/L & 5.3 & 0.50 & 9.4 \\
\hline$\Delta$ Glucose (basal to peak), $\mathrm{mmol} / \mathrm{L}$ & 2.8 & 1.37 & 48.4 \\
\hline Basal L-lactate, $\mathrm{mmol} / \mathrm{L}$ & 0.6 & 0.25 & 44.7 \\
\hline$\Delta$ L-lactate (basal to peak), mmol/L & 0.5 & 0.31 & 60.8 \\
\hline Basal insulin, $\mu \mathrm{g} / \mathrm{L}$ & 0.18 & 0.09 & 52.3 \\
\hline$\Delta$ Insulin (basal to peak), $\mu \mathrm{g} / \mathrm{L}$ & 7.3 & 6.48 & 88.9 \\
\hline Basal NEFA ${ }^{2}$ concentration, $\mathrm{mmol} / \mathrm{L}$ & 0.17 & 0.08 & 46.5 \\
\hline$\Delta$ NEFA (basal to $1 \mathrm{~h}), \mathrm{mmol} / \mathrm{L}$ & 0.07 & 0.07 & 89.7 \\
\hline \multicolumn{4}{|l|}{ Fasting challenge } \\
\hline$\Delta$ Glucose $(15$ to $24 \mathrm{~h}), \mathrm{mmol} / \mathrm{L}$ & 1.2 & 0.28 & 23.3 \\
\hline Fasting glucose $(24 \mathrm{~h}), \mathrm{mmol} / \mathrm{L}$ & 3.8 & 0.46 & 12.2 \\
\hline$\Delta \mathrm{NEFA}(15$ to $24 \mathrm{~h}), \mathrm{mmol} / \mathrm{L}$ & 0.11 & 0.13 & 112.9 \\
\hline Fasting NEFA $(24 \mathrm{~h}), \mathrm{mmol} / \mathrm{L}$ & 0.45 & 0.12 & 27.7 \\
\hline$\Delta{ }^{13} \mathrm{C}$ urea $(6$ to $15 \mathrm{~h})$, atom $\%$ & 0.027 & 0.009 & 34.2 \\
\hline \multicolumn{4}{|l|}{ Immunology } \\
\hline IgG specific to $\mathrm{HuSa}$, maximum response, titer & 5.5 & 1.53 & 27.6 \\
\hline IgM specific to HuSa, maximum response, titer & 1.3 & 0.93 & 69.0 \\
\hline \multicolumn{4}{|l|}{ Behavior and stress } \\
\hline \multicolumn{4}{|l|}{ Human approach test } \\
\hline Approach phase ${ }^{3}$ score $(0$ or 1$)$ & 0.1 & & \\
\hline Touch phase, ${ }^{3}$ score $(1$ to 5$)$ & 2.9 & & \\
\hline \multicolumn{4}{|l|}{ Restraint test } \\
\hline Basal cortisol, nmol/L & 2.3 & 3.19 & 137.7 \\
\hline$\Delta$ Cortisol, $\mathrm{nmol} / \mathrm{L}$ & 2.1 & 4.63 & 221.4 \\
\hline \multicolumn{4}{|l|}{ Behavior during weighing } \\
\hline Toward weighing scale, ${ }^{4}$ score $(1$ to 5$)$ & 3.7 & & \\
\hline On weighing scale, ${ }^{4}$ score ( 1 to 4$)$ & 1.4 & & \\
\hline Activity, $\%$ of time standing & 12.0 & 4.28 & 35.6 \\
\hline \multicolumn{4}{|l|}{ Other } \\
\hline IGF-1, $\mu \mathrm{g} / \mathrm{L}$ & 146.3 & 41.71 & 28.5 \\
\hline Calf shape, $\mathrm{cm}^{2} / \mathrm{kg}$ of $\mathrm{BW}$ & 137.2 & 5.0 & 3.7 \\
\hline
\end{tabular}

${ }^{1}$ For fecal $\mathrm{DM}$ content and $\mathrm{pH}, \mathrm{n}=100$. For retention time, $\mathrm{n}=76$. For the feeding motivation test with milk replacer and for drinking speed, $\mathrm{n}=106$. For all variables regarding postabsorptive metabolism, $\mathrm{n}=115$ except for $\Delta{ }^{13} \mathrm{C}$ urea $(6$ to $15 \mathrm{~h}$ ), where $\mathrm{n}=113$. For the human approach test, restraint test, and behavior during weighing, $\mathrm{n}=116$. For the human serum albumin (HuSa) challenge, $\mathrm{n}=105$ for $\operatorname{IgG}$ and $\mathrm{n}=106$ for IgM. ${ }^{2} \mathrm{NEFA}=$ nonesterified fatty acids.

${ }^{3}$ The human approach test was performed twice and the 2 scores were averaged per phase. For the approach phase, the number of calves with score $0,0.5$, and 1 were 105, 9, and 3, respectively. For the touch phase, 11 calves scored 1,8 calves scored $1.5,8$ calves scored 2,16 calves scored $2.5,25$ calves scored 3,19 calves scored 3.5 , and 30 calves scored 4 .

${ }^{4}$ For the behavior toward the weighing scale, the number of calves with score $1,2,3,4$, and 5 were $0,2,63$, 24 , and 28 , respectively. For the behavior on the weighing scale, the number of calves with score $1,2,3$, and 4 were $84,23,8$, and 2 , respectively. 

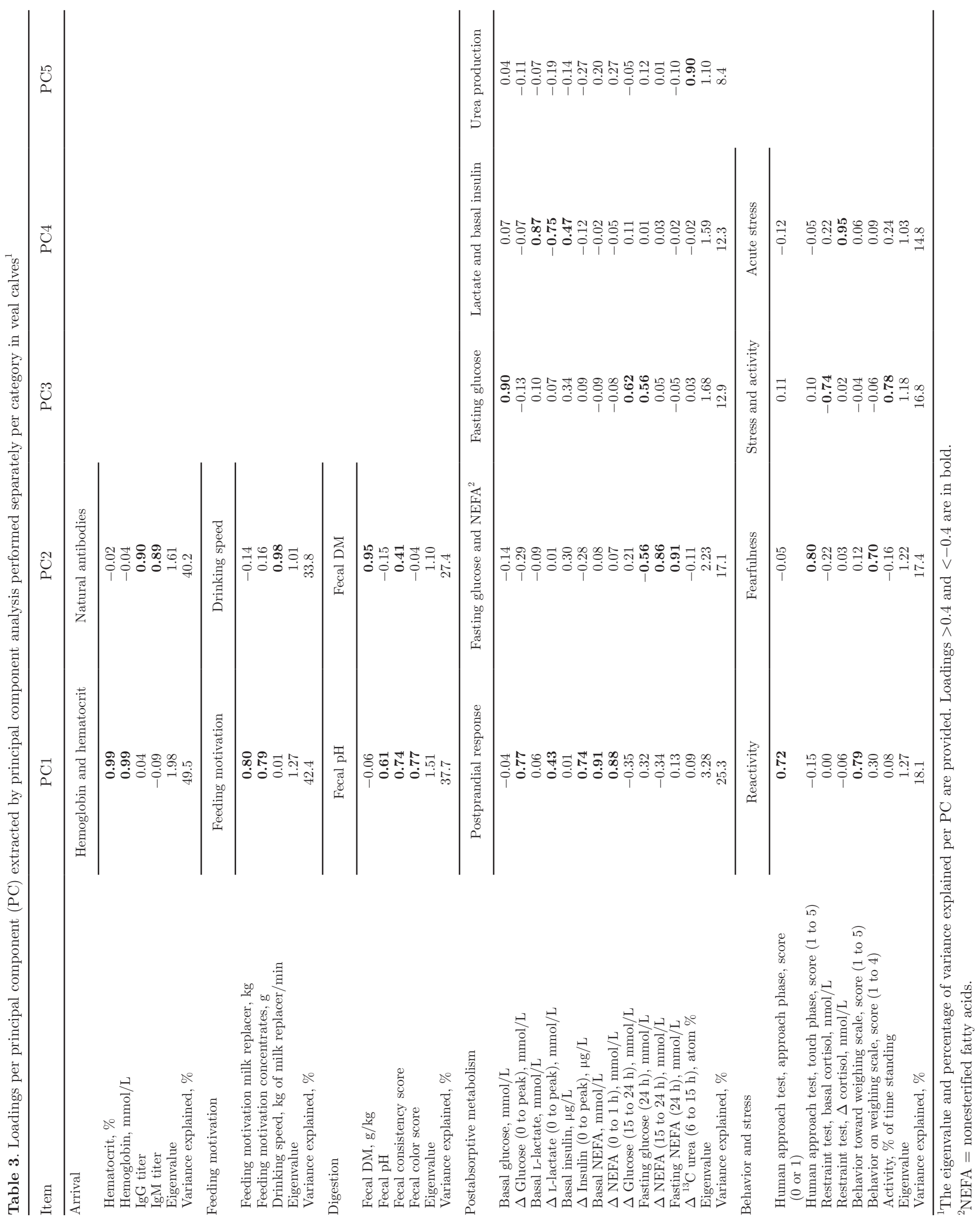
were retained, accounting for $76 \%$ of the total variance. For the category behavior and stress, 4 PC (reactivity, fearfulness, stress and activity, and acute stress) were retained, accounting for $67 \%$ of the total variance.

\section{Relation Between Early Life Measurements and Growth Performance in Period 2}

The ADG in period 2 tended to be greater for control calves $(1,292 \pm 111 \mathrm{~g} / \mathrm{d})$ than for GFG calves $(1,267$ $\pm 103 \mathrm{~g} / \mathrm{d} ; P=0.085)$. Solid feed intake in period 2 was unaffected by MR treatment $(P=0.89)$. Solid feed and MR intake averaged $81 \pm 18.2$ and $222 \pm 1.3 \mathrm{~kg}$, respectively, in period 2 .

The effects of selected PC and separate variables from period 1 on ADG and adjusted ADG in period 2 are presented in Table 4 . The $\mathrm{PC}$ drinking speed $(P$ $=0.003)$, the $\mathrm{PC}$ natural antibodies $(P=0.044)$, the interaction between the $\mathrm{PC}$ reactivity and $\mathrm{MR}$ treatment $(P=0.052)$, the $\mathrm{PC}$ fearfulness $(P=0.032)$, IGF-1 concentration $(P=0.003)$, and the specific IgM response to HuSa $(P=0.021)$ affected ADG in period 2. Variance explained by the model and by pen $\left(\mathrm{R}^{2}\right)$ were 19.9 and $19.2 \%$, respectively. Adjusted variance explained by the model (adjusted $\mathrm{R}^{2}$ ) was $17.3 \%$.

Effects of the $\mathrm{PC}$ fasting glucose $(P$ interaction $=$ $0.035)$, the $\mathrm{PC}$ fecal $\mathrm{pH}(P$ interaction $=0.057)$, the $\mathrm{PC}$ drinking speed $(P=0.063$ and interaction $=0.088)$, and the $\mathrm{PC}$ natural antibodies $(P$ interaction $=0.095)$ on adjusted ADG in period 2 differed between the MR treatments. Variance explained by the model and by pen $\left(\mathrm{R}^{2}\right)$ was 10.8 and $30.1 \%$, respectively. Adjusted variance explained by the model (adjusted $\mathrm{R}^{2}$ ) was $6.5 \%$.

Results of the secondary PCA are presented in Table 5. Ten secondary PC (sPC) were retained, accounting for $74 \%$ of the total variance. For 7 out of $10 \mathrm{sPC}$, at least $2 \mathrm{PC}$ from different categories loaded within a sPC.

\section{DISCUSSION}

\section{PCA per Category of Early Life Measurements}

Calves were characterized using targeted challenges in early life. We subjected data from these measurements in early life to PCA with the dual objective of data reduction and scaling of variables for subsequent multiple regression analysis. It should be noted that PCA is based on associations and that resulting loading patterns do not necessarily reflect causal relations. However, within each category, most loading patterns represented well-established relations and could therefore be labeled with a brief description.

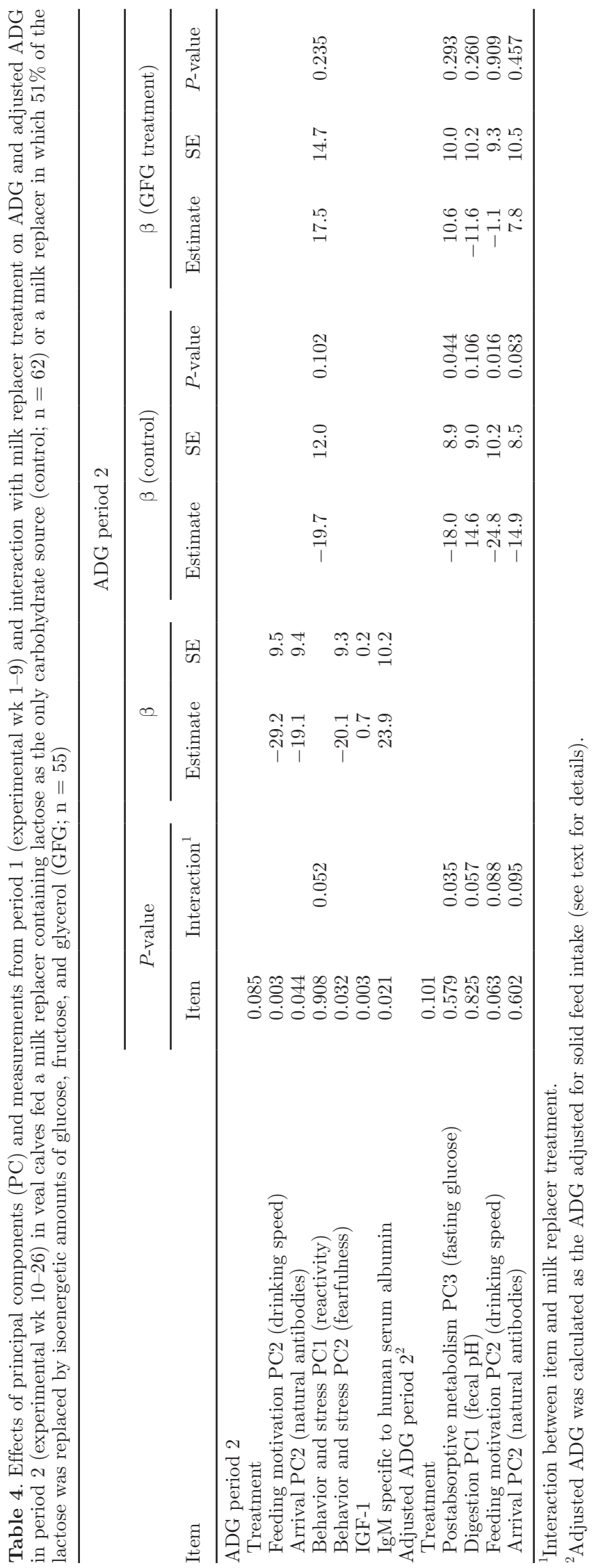


Table 5. Loadings per secondary principal component (sPC) extracted by secondary principal component analysis ${ }^{1}$

\begin{tabular}{|c|c|c|c|c|c|c|c|c|c|c|}
\hline Item & sPC1 & $\mathrm{sPC} 2$ & sPC3 & $\mathrm{sPC} 4$ & sPC5 & sPC6 & sPC7 & sPC8 & sPC9 & sPC10 \\
\hline Arrival PC2 & 0.01 & -0.02 & 0.04 & 0.04 & -0.02 & -0.05 & 0.87 & 0.05 & -0.01 & -0.03 \\
\hline Feeding motivation PC1 & 0.02 & -0.05 & 0.03 & 0.03 & -0.01 & 0.00 & -0.04 & -0.14 & -0.02 & 0.93 \\
\hline Digestion PC1 & 0.40 & -0.03 & 0.37 & 0.23 & 0.45 & 0.19 & 0.00 & -0.31 & 0.00 & -0.21 \\
\hline Digestion PC2 & 0.06 & -0.06 & -0.23 & 0.59 & -0.19 & -0.03 & -0.34 & -0.08 & -0.02 & -0.30 \\
\hline Postabsorptive metabolism PC1 & 0.04 & 0.07 & 0.04 & -0.10 & 0.16 & 0.69 & -0.24 & 0.00 & 0.28 & 0.03 \\
\hline Postabsorptive metabolism PC4 & -0.04 & -0.04 & -0.06 & 0.07 & 0.82 & -0.11 & -0.01 & 0.13 & 0.05 & 0.02 \\
\hline Postabsorptive metabolism PC5 & 0.04 & 0.81 & -0.15 & -0.19 & 0.09 & 0.10 & 0.04 & 0.03 & -0.16 & -0.13 \\
\hline Behavior and stress PC1 & 0.02 & -0.08 & 0.04 & 0.77 & 0.23 & 0.00 & 0.20 & 0.08 & -0.05 & 0.17 \\
\hline Behavior and stress $\mathrm{PC} 2$ & -0.05 & -0.10 & -0.07 & 0.08 & -0.32 & 0.75 & 0.13 & 0.03 & -0.15 & -0.02 \\
\hline Behavior and stress PC3 & 0.07 & -0.10 & 0.00 & -0.04 & 0.05 & 0.06 & 0.00 & -0.11 & 0.90 & -0.02 \\
\hline Behavior and stress PC4 & 0.13 & -0.36 & 0.61 & -0.05 & -0.01 & -0.02 & -0.37 & 0.20 & -0.08 & 0.09 \\
\hline IGF-1 concentration & 0.74 & 0.26 & -0.18 & 0.18 & 0.01 & 0.07 & -0.03 & -0.03 & 0.23 & 0.13 \\
\hline
\end{tabular}

${ }^{1}$ The eigenvalue and percentage of variance explained per sPC are provided. Loadings $>0.4$ and $<-0.4$ are in bold.

Arrival. High positive loadings in $\mathrm{PC} 1$ for the $\mathrm{Hb}$ concentration and the hematocrit level measured at arrival are in agreement with the positive relation between $\mathrm{Hb}$ and hematocrit found in calves (Rice et al., 1967). Principal component 2 had high positive loadings for natural IgG and IgM antibody titers. These PC together indirectly provide information on the background and the first $2 \mathrm{wk}$ of life of the calves before arrival. For instance, $\mathrm{Hb}$ and hematocrit values are lower for newborn calves from primiparous cows than from multiparous cows (Kume and Tanabe, 1993, 1996), and the IgG concentration in plasma of neonatal calves is related to colostrum intake (Hammon and Blum, 1998). However, serum IgG and IgM decrease in calves after birth, and endogenous IgG and IgM production starts between 8 and $16 \mathrm{~d}$ of age (Husband et al., 1972), indicating that the IgG and IgM titers determined in our experiment are a combination of colostral antibodies and antibodies endogenously produced by the calf.

Feeding Motivation. Principal component 1 had high positive loadings for intake during the ad libitum intake tests with MR and concentrates, indicating a positive association in feeding motivation for both MR and concentrates. This is in agreement with the positive relation between MR refusals and solid feed refusals in later life $(\mathrm{r}=0.37, P<0.001)$. Only the variable drinking speed loaded on PC2, and therefore PC2 was mainly associated with drinking speed.

Digestion. Principal component 1 had high positive loadings for fecal $\mathrm{pH}$, fecal consistency score, and fecal color score, and PC2 had high positive loadings for fecal DM content and fecal consistency score. Fecal $\mathrm{DM}$ content and $\mathrm{pH}$ did not load on the same PC, indicating that variation in fecal $\mathrm{pH}$ was not associated with variation in fecal DM content. A positive relation between fecal $\mathrm{DM}$ content and $\mathrm{pH}$ was found in calves in which intestinal fermentation was induced by the feeding of starch with the MR (Gilbert et al., 2015a, b). Variation in fecal $\mathrm{pH}$ and fecal DM content in the current study was therefore probably not related to intestinal fermentation.

Postabsorptive Metabolism. Principal component 1 had high positive loadings on the postprandial increase of plasma glucose, insulin, and L-lactate and the postprandial decrease in plasma NEFA. This postprandial response after ingestion of the MR meal is in agreement with the postprandial patterns found in milk-fed calves (Hugi et al., 1997; Vicari et al., 2008). Principal component 2 suggests a negative relation between blood glucose and NEFA concentrations during fasting, which can be attributed to increased release of NEFA from adipose tissue at low insulin:glucagon ratios (as reviewed by Holtenius and Holtenius, 1996), which occurs during fasting when plasma glucose levels drop. Principal component 3 is associated with fasting glucose concentrations, as the decrease in glucose concentration during fasting was highly related to the glucose concentration at $t=15 \mathrm{~h}(\mathrm{r}=0.43, P<0.001)$. Principal component 5 was primarily associated with the estimation of urea production.

Behavior and Stress. The PCA of behavioral and cortisol responses to human approach and restraint tests and during weighing produced $4 \mathrm{PC}$ with no crossloading. This finding agrees with other studies in which calves were subjected to behavioral tests and supports the idea that responsiveness of calves to challenge is mediated by multiple underlying temperamental traits (Kilgour et al., 2006; Petherick et al., 2009; Graunke 
et al., 2013). The withdrawal reaction of calves to an outstretching arm and the movement score during confinement in a weighing scale are believed to reflect fear of humans and flightiness or nervousness, respectively; PC2 was therefore labeled as fearfulness. Basal cortisol concentration and activity level were described as stress and activity in PC3. These 2 separate PC are in agreement with the suggested model of responsiveness in calves along the 2 independent axes fearfulness and activity, which combined could represent the coping style of a calf (van Reenen et al., 2005). The distance that had to be covered by the calves during routine weighing differed between calves. Distance to the weighing scale was positively correlated with the behavior toward the weighing scale $(\mathrm{r}=0.45, P<0.001)$ and behavior on the weighing scale $(\mathrm{r}=0.20, P=0.021)$. Future studies including such behavioral observations should therefore equalize the walking distance toward the weighing scale between calves.

\section{Relation Between Early Life Measurements and Growth Performance in Period 2}

Our first objective was to explain variation in growth performance of healthy veal calves by variation in physiological responses to specific challenges in early life. Early life characteristics explained $17 \%$ of the variation in growth performance in later life. The ADG in later life was positively related to early life IGF-1 concentration and specific IgM response to HuSa and negatively related to drinking speed, plasma natural antibodies at arrival, and fearfulness in early life. The positive relation between IGF-1 concentration and growth performance in cattle has been reported before (Lund-Larsen et al., 1977; Kerr et al., 1991), although Kerr et al. (1991) concluded that the predictive value of IGF-1 for final BW was low. In our data, early life IGF-1 concentration was not related to later life ADG adjusted for solid feed intake, indicating that IGF-1 is more related to solid feed intake than to feed efficiency. The negative relation between drinking speed and ADG in later life could have been partly caused by solid feed intake because high drinking speed and solid feed intake were negatively related $(\mathrm{r}=-0.16, P=0.09)$. However, drinking speed was still negatively related to ADG after adjusting for solid feed intake, indicating that drinking speed also affected feed efficiency. Interestingly, a negative relation between residual feed intake (a measure of feed efficiency) and rate of eating has been reported for beef cattle as well (Bingham et al., 2009). The negative relation between fearfulness and ADG in veal calves is in agreement with the generally reported finding that beef cattle with fearful or excitable temperament traits exhibit lower ADG than calmer animals (Müller and von Keyserlingk, 2006). Temperamental characteristics and growth performance are often measured at the same time, but our data indicate that these characteristics also have a predictive value for later life growth performance. The mechanism behind the association between behavioral responsiveness to challenge and ADG in cattle is not clear, but it has been suggested that fearfulness negatively affects metabolism or feed efficiency (Cooke, 2014). Interestingly, however, in the present study fearfulness was no longer related to ADG adjusted for solid feed refusals. This might indicate that fearfulness enhanced the occurrence of feed refusalswhich in turn attenuated ADG - rather than affected metabolism or feed efficiency. We applied a restricted feeding schedule to minimize variation in ADG related to variation in feed intake. However, refusals of solid feed occurred, resulting in variation in solid feed intake between calves (the CV of solid feed intake in later life was $22 \%$ ). Therefore, the relation between growth performance in later life and early life measurements were at least in part related to solid feed and total energy intake.

Variation in ADG adjusted for solid feed refusals represents variation in feed efficiency. Early life characteristics explained only $7 \%$ of variation in feed efficiency in later life. Mainly interactions between early life characteristics and MR treatment affected feed efficiency significantly. Fasting plasma glucose was negatively related to feed efficiency in control calves and positively, although numerically, related to feed efficiency in GFG calves. Similarly, the relation between feed efficiency and fecal $\mathrm{pH}$, drinking speed, and plasma natural antibodies at arrival differed between control calves and GFG calves. Drinking speed and fasting plasma glucose loaded positively on sPC1 in the secondary PCA, indicating that these early life characteristics could have a common underlying mechanism, which related negatively to feed efficiency in later life in control calves. Regardless of the mechanisms underlying these significant interactions, the early life characteristics (fasting plasma glucose, fecal $\mathrm{pH}$, drinking speed, and plasma natural antibodies at arrival) can potentially be used for screening calves in early life on their ability to cope with MR varying in lactose content.

A substantial part of the variation in feed efficiency (>90\%) remained unexplained. This could indicate that a large part of the variation cannot be predicted by early life characteristics or that a large part of the variation is attributable to factors not taken into account in this study. In our study, utmost care was taken to prevent taking observations from calves during periods of clinical disease. However, variation in health inevitably occurred and may have affected some observations in early life or feed efficiency in later life. Individual medi- 
cal treatments in later life were registered for 23 calves. Days on medical treatment and adjusted ADG in later life were negatively related $(\mathrm{r}=-0.19, P=0.040)$, indicating that clinical signs of illness or the medical treatment itself affected feed efficiency. The percentage of variance explained in feed efficiency increased from 6.5 to $11 \%$ when excluding the 23 calves that had received individual medical treatment, indicating that clinical disease contributed to interindividual variation in feed efficiency.

The effect of variation in health status or subclinical disease within our setting of minimized clinical disease is further illustrated by associations between calves housed together in one pen. Gastrointestinal and respiratory disorders often start localized within the stables. Usually, when $>10 \%$ of the calves have clinical signs of illness, metaphylactic treatments are applied to the complete batch of calves. This procedure is reflected in the substantially greater use of group antimicrobial treatment than individual antimicrobial treatment in veal systems (Pardon et al., 2012). Calves within close vicinity to an infected calf will be exposed to the pathogen and possibly subsequent disease, whereas clinical disease will likely be prevented in calves housed farther away. Therefore, calves within a pen affect each other more than calves between pens. This is also reflected in the large percentage (i.e., 30\%) of variation in feed efficiency that was associated with the random pen effect in our study, although factors other than health status also contribute to this pen effect. This emphasizes the importance of health status in explaining variation in feed efficiency in veal calves. Inflammatory status could contribute to variation in feed efficiency. For instance, hepatic expression of genes associated with inflammatory processes differed in beef cattle divergent for residual feed intake (Alexandre et al., 2015; Paradis et al., 2015). Mitochondrial function might also explain variation in feed efficiency. A higher mitochondrial respiration rate was found, for instance, in muscle tissue of beef steers with a low residual feed intake compared with beef steers with a high residual feed intake (Kolath et al., 2006). Electron leakage and $\mathrm{H}_{2} \mathrm{O}_{2}$ production was reduced in muscle mitochondria of pigs genetically selected for low residual feed intake (Grubbs et al., 2013). Indicators of inflammation and mitochondrial function should be included in future studies to evaluate their contribution to interindividual variation in feed efficiency in veal calves.

\section{Secondary PCA}

A secondary PCA was performed to evaluate whether the categories in early life had common underlying mechanisms. Seven of 10 retained sPC had high load- ings on PC from different categories, indicating that these categories have common underlying mechanisms. For instance, drinking speed, fasting plasma glucose, and IGF-1 concentration were positively associated in sPC1. The positive association between fasting plasma glucose concentrations and IGF-1 concentration in the basal plasma sample is in agreement with data presented by Chelikani et al. (2004), where lowered plasma glucose concentrations coincided with lowered plasma IGF-1 concentrations in response to fasting in dairy cattle. In addition, plasma glucose and IGF-1 concentrations were positively related to plasma leptin concentrations (Chelikani et al., 2004), an important hormone in regulating feed intake (reviewed by Ahima and Flier, 2000). When plasma glucose and IGF-1 concentrations decrease in response to fasting, leptin concentrations decrease as well, which stimulates feed intake. In our study, glucose and IGF-1 concentrations were positively associated with drinking speed, indicating that leptin is probably not the underlying mechanism in sPC1. Regardless of the underlying mechanisms, the associations found by secondary PCA suggest that the responses of calves to challenges related to feeding motivation, digestion, postabsorptive metabolism, and behavior cannot be interpreted as separately functioning systems but rather contribute together to the physiology of the animal.

\section{CONCLUSIONS}

Early life characterization of feeding motivation, digestion, postabsorptive metabolism, immunology, and behavior and stress in veal calves explained $17 \%$ of the variation in growth performance in later life. When growth performance was adjusted to equal solid feed intake, only $7 \%$ of the variation in standardized ADG (in fact reflecting variation in feed efficiency) could be explained by early life measurements. This indicates that $>90 \%$ of the variation in feed efficiency in later life could not be explained by early life characterization of calves. It is hypothesized that variation in health status explains substantial variation in feed efficiency in veal calves. Relations between fasting plasma glucose concentrations, fecal $\mathrm{pH}$, drinking speed, and plasma natural antibodies in early life and feed efficiency in later life depended on MR composition. These measurements are therefore potential tools for screening calves in early life on their ability to cope with MR varying in lactose content.

\section{ACKNOWLEDGMENTS}

The authors thank Klaas Boeder, Bart Evers, Ewart van Voorst, Henrico Boon (VanDrie Group, 
Scherpenzeel, the Netherlands), Dirk Anjema (Livestock Research, Wageningen University and Research, Wageningen, the Netherlands), Ger de Vries-Reilingh (Adaptation Physiology Group, Wageningen University), Nuno Mateus Rodrigues, Lonneke Jansen, Lydia Kroon, Tamme Zandstra (Animal Nutrition Group, Wageningen University) for their assistance and Aart Lammers (Adaptation Physiology Group, Wageningen University) for his advice regarding immunological measurements. This project was jointly financed by the European Union; European Regional Development Fund; and The Ministry of Economic Affairs, Agriculture and Innovation; Peaks in the Delta; the Municipality of Groningen (Groningen, the Netherlands); the province of Groningen (Groningen, the Netherlands); the province of Fryslan (Leeuwarden, the Netherlands); the province of Drenthe (Assen, the Netherlands); and the Dutch Carbohydrate Competence Center (Groningen, the Netherlands). Financial support was also provided by Tereos Syral, VanDrie Group, and Wageningen University.

\section{REFERENCES}

Ahima, R. S., and J. S. Flier. 2000. Leptin. Annu. Rev. Physiol. $62: 413-437$.

Akinyele, I. O., and K. E. Harshbarger. 1983. Performance of young calves fed soybean protein replacers. J. Dairy Sci. 66:825-832.

Alexandre, P. A., L. J. A. Kogelman, M. H. A. Santana, D. Passarelli, L. H. Pulz, P. Fantinato-Neto, P. L. Silva, P. R. Leme, R. F. Strefezzi, L. L. Coutinho, J. B. S. Ferraz, J. P. Eler, H. N. Kadarmideen, and H. Fukumasu. 2015. Liver transcriptomic networks reveal main biological processes associated with feed efficiency in beef cattle. BMC Genomics 16:1073.

Barea, R., S. Dubois, H. Gilbert, P. Sellier, J. Van Milgen, and J. Noblet. 2010. Energy utilization in pigs selected for high and low residual feed intake. J. Anim. Sci. 88:2062-2072.

Benvenutti, M. A., D. B. Coates, J. Bindelle, D. P. Poppi, and I. J. Gordon. 2014. Can faecal markers detect a short term reduction in forage intake by cattle? Anim. Feed Sci. Technol. 194:44-57.

Bingham, G. M., T. H. Friend, P. A. Lancaster, and G. E. Carstens. 2009. Relationship between feeding behavior and residual feed intake in growing Brangus heifers. J. Anim. Sci. 87:2685-2689.

Blair, H. T., S. N. McCutcheon, and D. D. S. Mackenzie. 1990. Physiological predictors of genetic merit. Pages 133-142 in Proc. 8th Conf. Aust. Assoc. Anim. Breed. and Genet., Palmerston North and Hamilton, NZ. G. Wickham, L. Baker, D. Johnson, C. Morris, R. Sumnar, A. Parry, T. Knight, S. Newman, C. Sosa, G. AhlbornBreier, C. Holmes, R. Purchas, M. McDonald, S. McCutcheon, D. Garrick, W. Parker, S. Morris, T. Broad, R. Jackson, J. Rendel, and H. Blair, ed. AAABG, Palmerston North, New Zealand.

Borderas, T. F., A. M. de Passillé, and J. Rushen. 2008. Behavior of dairy calves after a low dose of bacterial endotoxin. J. Anim. Sci. 86:2920-2927.

Cafe, L. M., D. L. Robinson, D. M. Ferguson, G. H. Geesink, and P. L. Greenwood. 2011. Temperament and hypothalamic-pituitaryadrenal axis function are related and combine to affect growth, efficiency, carcass, and meat quality traits in Brahman steers. Domest. Anim. Endocrinol. 40:230-240.

Chelikani, P. K., J. D. Ambrose, D. H. Keisler, and J. J. Kennelly. 2004 Effect of short-term fasting on plasma concentrations of leptin and other hormones and metabolites in dairy cattle. Domest. Anim. Endocrinol. 26:33-48.
Cooke, R. F. 2014. Temperament and acclimation to human handling influence growth, health, and reproductive responses in Bos taurus and Bos indicus cattle. J. Anim. Sci. 92:5325-5333.

Dai, X., X. Fang, F. Su, M. Yang, H. Li, J. Zhou, and R. Xu. 2010. Accurate analysis of urea in milk and milk powder by isotope dilution gas chromatography-mass spectrometry. J. Chromatogr. B Analyt. Technol. Biomed. Life Sci. 878:1634-1638.

Elbers, A. R. W., L. A. Den Hartog, M. W. A. Verstegen, and T. Zandstra. 1989. Between- and within-herd variation in the digestibility of feed for growing-finishing pigs. Livest. Prod. Sci. 23:183-193.

Gilbert, H., S. Alaïn, J. Bidanel, H. Lagant, Y. Billon, P. Guillouet, J. Noblet, and P. Sellier. 2009. Divergent selection for residual feed intake in the growing pig: Correlated effects on feeding behaviour. J. Rech. Porcine 41:149-150.

Gilbert, M. S., A. J. Pantophlet, H. Berends, A. M. Pluschke, J. J. G. C. van den Borne, W. H. Hendriks, H. A. Schols, and W. J. J. Gerrits. 2015a. Fermentation in the small intestine contributes substantially to intestinal starch disappearance in calves. J. Nutr. 145:1147-1155.

Gilbert, M. S., A. J. Pantophlet, J. J. G. C. van den Borne, W. H. Hendriks, H. A. Schols, and W. J. J. Gerrits. 2016. Effects of replacing lactose from milk replacer by glucose, fructose, or glycerol on energy partitioning in veal calves. J. Dairy Sci. 99:1121-1132.

Gilbert, M. S., J. J. G. C. van den Borne, H. Berends, A. J. Pantophlet, H. A. Schols, and W. J. J. Gerrits. 2015b. A titration approach to identify the capacity for starch digestion in milk-fed calves. Animal 9:249-257.

Graunke, K. L., G. Nürnberg, D. Repsilber, B. Puppe, and J. Langbein. 2013. Describing temperament in an ungulate: A multidimensional approach. PLoS One 8:e74579.

Grubbs, J. K., A. N. Fritchen, E. Huff-Lonergan, J. C. M. Dekkers, N. K. Gabler, and S. M. Lonergan. 2013. Divergent genetic selection for residual feed intake impacts mitochondria reactive oxygen species production in pigs. J. Anim. Sci. 91:2133-2140.

Hammon, H. M., and J. W. Blum. 1998. Metabolic and endocrine traits of neonatal calves are influenced by feeding colostrum for different durations or only milk replacer. J. Nutr. 128:624-632.

Herd, R. M., and P. F. Arthur. 2009. Physiological basis for residual feed intake. J. Anim. Sci. 87:E64-E71.

Herd, R. M., V. H. Oddy, and E. C. Richardson. 2004. Biological basis for variation in residual feed intake in beef cattle. 1. Review of potential mechanisms. Aust. J. Exp. Agric. 44:423-430.

Holtenius, P., and K. Holtenius. 1996. New aspects of ketone bodies in energy metabolism of dairy cows: A review. Zentralbl Veterinarmed A 43:579-587.

Hugi, D. P., V. D. Bracher, L. Tappy, and J. W. Blum. 1997. Postprandial hydrogen breath excretion, plasma lactate concentration, glucose metabolism and insulin levels in veal calves. J. Anim. Physiol. Anim. Nutr. (Berl.) 78:42-48.

Husband, A. J., M. R. Brandon, and A. K. Lascelles. 1972. Absorption and endogenous production of immunoglobulins in calves. Aust. J. Exp. Biol. Med. Sci. 50:491-498.

ISO (International Organization for Standardization). 1999a. Animal feeding stuffs - Determination of fat content. Standard number 6492. ISO, Geneva, Switzerland.

ISO (International Organization for Standardization). 1999b. Animal feeding stuffs - Determination of moisture and other volatile matter content. Standard number 6496. ISO, Geneva, Switzerland.

ISO (International Organization for Standardization). 2002. Animal feeding stuffs-Determination of crude ash. Standard number 5984. ISO, Geneva, Switzerland.

ISO (International Organization for Standardization). 2005. Animal feeding stuffs - Determination of nitrogen content and calculation of crude protein content. Part 2: Block digestion/steam distillation method. Standard number 5983-2. ISO, Geneva, Switzerland.

Kerr, D. E., B. Laarveld, M. I. Fehr, and J. G. Manns. 1991. Profiles of serum IGF-I concentrations in calves from birth to eighteen months of age and in cows throughout the lactation cycle. Can. J. Anim. Sci. 71:695-705.

Kilgour, R. J., G. J. Melville, and P. L. Greenwood. 2006. Individual differences in the reaction of beef cattle to situations involving 
social isolation, close proximity of humans, restraint and novelty. Appl. Anim. Behav. Sci. 99:21-40.

Kolath, W. H., M. S. Kerley, J. W. Golden, and D. H. Keisler. 2006. The relationship between mitochondrial function and residual feed intake in Angus steers. J. Anim. Sci. 84:861-865.

Kume, S., and S. Tanabe. 1993. Effect of parity on colostral mineral concentrations of Holstein cows and value of colostrum as a mineral source for newborn calves. J. Dairy Sci. 76:1654-1660.

Kume, S., and S. Tanabe. 1996. Effect of supplemental lactoferrin with ferrous iron on iron status of newborn calves. J. Dairy Sci. 79:459-464.

Labussière, E., S. Dubois, J. van Milgen, G. Bertrand, and J. Noblet. 2008. Effects of dietary crude protein on protein and fat deposition in milk-fed veal calves. J. Dairy Sci. 91:4741-4754.

Lensink, B. J., C. G. van Reenen, B. Engel, T. B. Rodenburg, and I. Veissier. 2003. Repeatability and reliability of an approach test to determine calves' responsiveness to humans: A brief report. Appl. Anim. Behav. Sci. 83:325-330.

Lund-Larsen, T. R., A. Sundby, V. Kruse, and W. Velle. 1977. Relation between growth rate, serum somatomedin and plasma testosterone in young bulls. J. Anim. Sci. 44:189-194

Moore, K. L., D. J. Johnston, H. U. Graser, and R. Herd. 2005. Genetic and phenotypic relationships between insulin-like growth factorI (IGF-I) and net feed intake, fat, and growth traits in Angus beef cattle. Aust. J. Agric. Res. 56:211-218.

Morin, D. E., G. C. McCoy, and W. L. Hurley. 1997. Effects of quality, quantity, and timing of colostrum feeding and addition of a dried colostrum supplement on immunoglobulin $\mathrm{G}_{1}$ absorption in Holstein bull calves. J. Dairy Sci. 80:747-753.

Müller, R., and M. A. G. von Keyserlingk. 2006. Consistency of flight speed and its correlation to productivity and to personality in Bos taurus beef cattle. Appl. Anim. Behav. Sci. 99:193-204.

NEN (Normalisatie en Normen). 1984. Milk, evaporated milk and dried milk-Determination of the nitrogen content according to Kjeldahl-Calculation of the crude protein content. Reference method no. 3198. NEN, Delft, the Netherlands.

Oosterveld, M. J. S., R. J. B. J. Gemke, J. R. Dainty, W. Kulik, C. Jakobs, and K. de Meer. 2005. Minimal sampling protocol for ac- curate estimation of urea production: A study with oral $\left[{ }^{13} \mathrm{C}\right]$ urea in fed and fasted piglets. Clin. Nutr. 24:97-104.

Paradis, F., S. Yue, J. R. Grant, P. Stothard, J. A. Basarab, and C. Fitzsimmons. 2015. Transcriptomic analysis by RNA sequencing reveals that hepatic interferon-induced genes may be associated with feed efficiency in beef heifers. J. Anim. Sci. 93:3331-3341.

Pardon, B., B. Catry, J. Dewulf, D. Persoons, M. Hostens, K. De Bleecker, and P. Deprez. 2012. Prospective study on quantitative and qualitative antimicrobial and anti-inflammatory drug use in white veal calves. J. Antimicrob. Chemother. 67:1027-1038.

Petherick, J. C., V. J. Doogan, R. G. Holroyd, P. Olsson, and B. K. Venus. 2009. Quality of handling and holding yard environment, and beef cattle temperament: 1 . Relationships with flight speed and fear of humans. Appl. Anim. Behav. Sci. 120:18-27.

Petherick, J. C., R. G. Holroyd, V. J. Doogan, and B. K. Venus. 2002. Productivity, carcass and meat quality of lot-fed Bos indicus cross steers grouped according to temperament. Aust. J. Exp. Agric. 42:389-398.

Rice, R. W., G. E. Nelms, and C. O. Schoonover. 1967. Effect of injectable iron on blood hematocrit and hemoglobin and weaning weight of beef calves. J. Anim. Sci. 26:613-617.

Richardson, E. C., and R. M. Herd. 2004. Biological basis for variation in residual feed intake in beef cattle. 2. Synthesis of results following divergent selection. Aust. J. Exp. Agric. 44:431-440.

Richardson, E. C., R. M. Herd, J. A. Archer, and P. F. Arthur. 2004. Metabolic differences in Angus steers divergently selected for residual feed intake. Aust. J. Exp. Agric. 44:441-452.

van Reenen, C. G., N. E. O'Connell, J. T. N. van der Werf, S. M. Korte, H. Hopster, R. B. Jones, and H. J. Blokhuis. 2005. Responses of calves to acute stress: Individual consistency and relations between behavioral and physiological measures. Physiol. Behav. 85:557-570.

Vicari, T., J. J. G. C. van den Borne, W. J. J. Gerrits, Y. Zbinden, and J. W. Blum. 2008. Postprandial blood hormone and metabolite concentrations influenced by feeding frequency and feeding level in veal calves. Domest. Anim. Endocrinol. 34:74-88. 